\title{
Imatinib-associated matrix metalloproteinase suppression in p16-positive squamous cell carcinoma compared to HPV-negative HNSCC cells in vitro
}

\author{
CLAUDIA UMBREIT ${ }^{1}$, CHRISTOPH ADERHOLD ${ }^{1}$, ANNE FABER ${ }^{1}$, ALEXANDER SAUTER ${ }^{1}$, \\ RALF-DIETER HOFHEINZ $^{2}$, JENS STERN-STRAETER ${ }^{1}$, KARL HOERMANN ${ }^{1}$ and JOHANNES DAVID SCHULTZ ${ }^{1}$ \\ ${ }^{1}$ Department of Otorhinolaryngology, Head and Neck Surgery, and ${ }^{2}$ Department of Hematology and Oncology, \\ University Hospital Mannheim, D-68167 Mannheim, Germany
}

Received January 14, 2014; Accepted March 13, 2014

DOI: $10.3892 /$ or.2014.3225

\begin{abstract}
Head and neck squamous cell carcinoma (HNSCC) is the sixth most common type of cancer worldwide. The growth and invasion of HNSCC are strongly influenced by the extracellular matrix (ECM), which is modified by matrix metalloproteinases (MMPs). The MMP family is still relevant to cancer research, as it promotes malignant transformation, cell proliferation and modulation of angiogenesis even in the early stages of cancer. The proteolytic processing of bioactive molecules by MMP-14 (MT1-MMP) causes severe abnormalities in connective tissue, defective angiogenesis and premature death. MMP-2 (gelatinase A) and MMP-14 also play a role in degradation of basement membrane and cell carcinoma invasion. Imatinib blocks the PTK receptor c-kit and forestalls its PTK activity. The aim of the present study was to investigate the expression pattern of MMP-14 and MMP-2 in human papilloma virus (HPV)-negative and p16-positive SCC and to evaluate the chemosensitivity of the tumour cells to the chemotherapeutic agents, imatinib and 5-fluorouracil (5-FU). We incubated the SCC cell lines with imatinib (18 and $30 \mu \mathrm{mol} / \mathrm{ml})$ and 5-FU (1 and $5 \mu \mathrm{mol} / \mathrm{ml})$ and detected MMP-14 and MMP-2 by immunohistochemistry and enzyme-linked immunosorbent assay (ELISA) after 48, 72, 120, 192 and $240 \mathrm{~h}$. We detected expression of MMP-2 and MMP-14 in all incubated tumour cell lines. With imatinib in particular, we found a reliable trend towards decreased MMP-2 and MMP-14 expression levels in p16-positive and p16-negative SCC tumour cell lines in addition to an induced apoptotic effect. We found statistically significant imatinib-induced suppression of MMP-2and MMP-14, dependent on the incubation time and the cell line. We detected a significant suppression of MMP-2 and MMP-14 especially in p16-negative HNSCC14C cells after prolonged
\end{abstract}

Correspondence to: Dr Claudia Umbreit, Department of Otorhinolaryngology, Head and Neck Surgery, University Hospital Mannheim, Theodor-Kutzer-Ufer 1-3, D-68167 Mannheim, Germany E-mail: claudia.umbreit@umm.de

Key words: 5-FU, imatinib, matrix metalloproteinases, MMP-14, MMP-2, extracellular matrix, head and neck squamous cell carcinoma, protein tyrosine kinase, human papillomavirus, epithelialmesenchymal transition treatment time with imatinib. Dose escalation of imatinib and 5-FU had no statistically significant effect on the expression of MMP-2 or MMP-14. The p16-positive SCC cells exhibited higher expression of total protein. We detected a significant suppression of MMP-2 and MMP-14 in all the incubated SCC cell lines, partially after treatment with imatinib. We found higher suppression of MMP-2 in the CERV196 cells after incubation with imatinib. We detected a reliable trend towards increased chemosensitivity of p16-positive tumour cells in vitro after treatment with imatinib. Extended studies and clinical trials are needed to further investigate these findings in HPV-associated HNSCC.

\section{Introduction}

Head and neck squamous cell carcinoma (HNSCC) is the sixth leading cancer in regards to incidence worldwide. The epidemiologic data vary between different geographical regions. Squamous cell carcinomas (SCC) accounts for more than $95 \%$ of all HNSCC cases (1). Approximately 644,000 new cases of HNSCC occur every year (2). The tumorigenesis of SCC results from a multistep accumulation of various genetic changes in squamous cells. These different changes increasingly enhance the ability of transformed cells to invade and proliferate (3). The heterogeneity of these alterations elucidates why tumours with the same clinical stage and localisation often show significant differences in their clinical outcome and treatment response $(4,5)$. Multimodal therapy for HNSCC includes surgery, chemoradiation and often the combination of these strategies (6). Chemotherapy is the primary treatment for advanced tumours. Multimodal tumour treatment reduces the quality of life of patients, and the psychosocial consequences are greater than that of other neoplasms. Despite new modalities in therapeutic strategies, the survival rate of SCC patients is still poor, and the overall 5-year survival rate of HNSCC patients has not improved over the past three decades $(3,7,8)$. The biological factors and pathways that cause locoregional and distant spreading of the neoplasms are not completely understood. Many biological markers have been characterized. Several proteins such as epidermal growth factor receptor (EGFR), p53, and matrix metalloproteinases (MMPs) have been described as potential markers for survival prediction in 
SCC (3). Targeting EGFR has been applied modestly to HNSCC tumours (9). Thus, new treatment modalities are needed to increase the long-term survival of patients with SCCs.

The main risk factors for the development of HNSCC are alcohol and tobacco consumption. Clinical and pathological evidence suggests that viral oncogenic human papillomavirus (HPV) infection is another crucial etiologic factor (10). The epidemiological, genetic, molecular and clinical profile of HPV-associated HNSCC cells appears to differ from that of tobacco and alcohol-induced HNSCC (non-HPV). HPV-positive oropharyngeal carcinomas are characterized by young age at onset, male predominance, and strong association with sexual behaviour (11,12). Kreimer and colleagues (13) analysed study locations and found that HPV prevalence of oral SCCs was similar in Europe (16.0\%) and North America (16.1\%) but significantly greater in Asia (33.0\%). In contrast, HPV prevalence of oropharyngeal SCCs was significantly higher in North America (47\%) compared with Europe (28\%). Patients with HPV-associated oropharyngeal cancer have a higher survival rate, which is attributed to good performance status and the presence of multiple polymorphisms form of the p53-related genes (14). The viral aetiology is linked to specific subtypes of HPV called high-risk HPV types, such as HPV16 and HPV18, especially those that arise from SCC of the tonsils and the tongue base (15). The process of HPV-associated malignant transformation depends on the presence of the viral oncogenes E6 and E7. The expression of E6 and E7 inhibits two tumoursuppressor proteins: p53 and retinoblastoma protein (pRb). The loss of several key regulative proteins activates dedifferentiation, proliferation and cell cycle progression of HPV-infected epithelial cells and facilitates induction of the transformed phenotype $(12,16)$. Loss of cell adhesion and transformation of epithelial cells to a mesenchymal phenotype is described as epithelialmesenchymal transition (EMT). EMT is a fundamental step in cancer invasion and progression. It is characterized by downregulation of epithelial-specific adhesive proteins (e.g., tight and adherent junction proteins such as E-cadherin), by induction of mesenchymal proteins such as vimentin and development of migratory attributes (17). In a model of breast cancer cell lines, Tester and colleagues (18) described MMP-14-mediated MMP-2 activation to delineate the EMT in breast cancer progression. The absence of MMP-9 led to the inability to activate MMP-2 and may have been responsible for their decreased motility, invasiveness and metastasis.

Matrix metalloproteinases (MMPs) represent a subgroup of the metzincin superfamily of proteases that form one of the several metalloendopeptidase families. Based on their specificity of the extracellular matrix (ECM) proteins, MMPs could be classified into collagenases, gelatinases, stromelysins and matrilysins (19). As gelatinases, MMPs play an important role in degrading the ECM. These enzymes are also associated with morphogenesis, organization, bone development, wound healing and cancer development (20-23). They represent a key role in tumour cell invasion of the basement membrane and stroma, blood vessel penetration, metastasis and tumour promotion (24). Surface expression of MMP-14 on ovarian cancer cells activates a tumour-stromal signalling pathway that promotes angiogenesis and tumour growth. Kaimal and colleagues (25) inhibited MMP-14-dependent invasion and metastasis in ovarian cancer by intraperitoneal administration of a monoclonal MMP-14 antibody. Bodnar and colleagues (2) suggested in laryngeal SCC that tumour cells with low MMP-14 expression invade tumour stroma and form metastases. MMP-2 has been evaluated in several types of cancer cells and appears to be associated with low-grade differentiation but also with promotion of tumour progression in, for example, head and neck cancer $(26,27)$.

Imatinib is a protein tyrosine-kinase inhibitor (PTKI) (Glivec $^{\circledR}$ or Gleevec ${ }^{\circledR}$, STI-571; Novartis, Basel, Switzerland) that is classified as a 2-phenylaminopyrimidine. Imatinib binds specifically at the tyrosine kinase domain in Abl (the Abelson poto-oncogene), c-kit and platelet-derived growth factor receptor (PDGFR). Bran and colleagues (28) showed that PDGFR plays an essential role in HNSCC growth. The activated protein tyrosine-kinase (PTK) c-kit enables other proteins that are necessary in the long-term survival of leukemic groups and proliferation (29). Imatinib impairs the immune system by inhibiting the T-cell pathway (30). The protein tyrosine-kinase features an essential element of the intracellular signalling pathway of cell growth, apoptosis and metastasis. Imatinib is used for its selectivity against BCR-ABL in the therapy of multiple cancers, most notably against chronic myeloid leukemia (CML). However, it is also appropriated for treatment against gastrointestinal stromal tumours (GISTs) or neurofibromatosis $(31,32)$.

5-Fluorouracil (5-FU) is an analogue of uracil that inhibits the nucleotide synthetic enzyme thymidylate synthase and forestalls normal function by incorporating into RNA and DNA. This antimetabolite drug is used to treat a wide range of cancers, such as colorectal, breast, head and neck and other neoplasia of the aerodigestive tract (33).

The aim of the present study was to evaluate the expression pattern of MMP-14 and MMP-2 in p16-positive SCC and HPV-negative HNSCC tumour cells. Furthermore, the chemosensitivity of p16-positive SCC cells was compared to non-HPV tumour cell lines after single drug treatment with 5-FU and imatinib as established anticancer regimes for head and neck tumours.

\section{Materials and methods}

Cell lines and culture. The two different HNSCC cell lines 11A and 14C (UMSCC11A/14C) were obtained from Dr T.E. Carey (University of Michigan, Ann Arbor, MI, USA). They were derived from human HNSCC of the larynx (HNSCC11A) and oral cavity (HNSCC14C). The p16-positive cell line CERV196 (CLS Cell Lines Service, Eppelheim, Germany) originated from a poorly differentiated xenotransplanted cervical carcinoma MRI-H-196. Cell cultures were carried out at $37^{\circ} \mathrm{C}$ in a fully humidified atmosphere with $5 \% \mathrm{CO}_{2}$ using Dulbecco's modified minimum essential medium (DMEM) (Fisher Scientific Co., Pittsburgh, PA, USA) supplemented with $10 \%$ fetal calf serum (FCS) and antibiotics (Life Technologies Inc., Gainthersburg, MD, USA). Imatinib was supplied by the manufacturer (Novartis, Nürnberg, Germany). Imatinib and 5-FU were stored at $4^{\circ} \mathrm{C}$ and dissolved in sterile water at the time of application. For incubation with HNSCC cell lines, different concentrations of 5-FU $(5 \mu \mathrm{mol} / \mathrm{ml})$ and imatinib $(18 \mu \mathrm{mol} / \mathrm{ml})$ were defined and used for stimulation for 48 to $240 \mathrm{~h}$. After performing the alamarBlue (AbD Serotec, Oxfordshire, UK) cell proliferation assay, selection of the different drug concentrations and times of stimulation were defined. Following 
incubation, the supernatants were collected together in sterile tubes and stored at $-20^{\circ} \mathrm{C}$ until further analysis.

Enzyme-linked immunosorbent assay (ELISA). MMP-14 and MMP-2 concentrations were determined by the ELISA technique (DMP2F0; R\&D Systems, Wiesbaden, Germany). The system utilised a solid-phase monoclonal antibody and an enzyme-linked polyclonal antibody against MMP-2 and MMP-14. The specificity of the anti-human antibodies in the ELISA kit were examined with sodium dodecyl sulphate polyacrylamide gel electrophoresis (SDS-PAGE) followed by western blotting. In accordance with the manufacturer's instructions, each assay measured $100 \mu \mathrm{l}$ of supernatant. All analyses and calibrations were performed in duplicate. Optical density was detected using a microplate reader at a wavelength of $540 \mathrm{~nm}$. Concentrations of MMP-2 and MMP-14 were reported as $\mathrm{ng} / \mathrm{ml}$. After 48, 72, 120, 192 and $240 \mathrm{~h}$ of incubation with $18 \mu \mathrm{mol} / \mathrm{ml}$ imatinib and $5 \mu \mathrm{mol} / \mathrm{ml} 5-\mathrm{FU}$, the expression of MMP-2 and MMP-14 was detected in the supernatants of the incubated cell cultures and untreated cell cultures.

Immunohistochemistry. Immunohistochemical analysis was performed using a monoclonal mouse anti-human antibody directed against MMP-2 and MMP-14 (ab7032/ab73879; Abcam, Cambridge, UK). Immunostaining was performed using the streptavidin horseradish method. Before performing immunohistochemistry, HNSCC cells were cultured in 8-well chambers overnight. After growing to confluency, cells were exposed to different concentrations of $5-\mathrm{FU}(5 \mu \mathrm{mol} / \mathrm{ml})$ and imatinib $(18$ or $30 \mu \mathrm{mol} / \mathrm{ml})$ for different incubation periods $(0,48,72,120$ and $240 \mathrm{~h}$ ). Subsequently, they underwent fixation with acetone and alcohol (2:1) and were then washed with phosphate-buffered saline solution (PBS). The following steps were executed by an automated staining system, Dako TechMate 500 (Dako, Hamburg, Germany). Cells were incubated with primary antibody solution for $30 \mathrm{~min}$ at room temperature using a 1:300 working solution of antibody to cells. Slices were washed three times with PBS for 5 min each time (Buffer kit; Dako). An immunoreaction was shown with the Dako ChemMate Detection kit according to the guidelines of the manufacturer (APAAP, mouse, no. K5000; Dako). Cells were incubated in sheep serum. An immunoreaction was demonstrated with the monoclonal mouse anti-human antibody MMP-2 and MMP-14 (ab7032/ab73879; Abcam). Incubation was followed by the addition of a specific biotinylated secondary antibody and streptavidin-biotin horseradish peroxidase complex (Amersham, Freiburg, Germany). To perform the peroxidase reaction, aminoethylcarbazole as chromogen was used. Before washing cells several times, endogenous peroxidase was blocked. For negative controls, all reagents except for the primary antibody were used. The sections received a counterstaining by Harris' hematoxylin for $30 \mathrm{sec}$ followed by dehydration in graded ethanol and coverslipping. The immunohistochemistry demonstrated that rates of MMP-2 and MMP-14 expression were determined semi-quantitatively. The staining intensity was as follows: strong reactivity, $>80 \%$ of the cells stained positive; moderate reactivity, $50-80 \%$ of the cells stained positive; and no positive cells.

Statistical analysis. Statistical analysis was performed in cooperation with Dr C. Weiss, Institute of Biomathematics,
Table I. Immunostaining score for MMP-14 in HNSCC11A, HNSCC14C and CERV196 cells.

\begin{tabular}{lcccc}
\hline Immunostaining & $48 \mathrm{~h}$ & $72 \mathrm{~h}$ & $120 \mathrm{~h}$ & $240 \mathrm{~h}$ \\
\hline Control group & & & & \\
HNSCC11A & ++ & ++ & +++ & +++ \\
HNSCC14C & ++ & +++ & ++ & +++ \\
CERV196 & ++ & ++ & +++ & ++ \\
imatinib 18 $\mu \mathrm{mol}$ & & & & \\
HNSCC11A & ++ & ++ & ++ & ++ \\
HNSCC14C & ++ & + & + & + \\
CERV196 & +++ & & ++ & ++ \\
imatinib 30 $\mu \mathrm{mol}$ & & & & \\
HNSCC11A & + & + & + & + \\
HNSCC14C & ++ & 0 & 0 & 0 \\
CERV196 & ++ & ++ & ++ & + \\
\hline
\end{tabular}

0 , no positive cells; + , weak immunostaining; ++ , moderate immunostaining; +++, strong immunostaining.

Faculty of Medicine, Mannheim, Germany. All data were expressed as the means. The differences in MMP expression between incubated cultures and control cultures were statistical analysed using Dunnett's test as part of generalised linear model (GLM) procedure. A p-value of $\leq 0.05$ was considered to indicate a statistically significant result.

\section{Results}

Immunohistochemistry. Immunhistochemical studies for MMP-14 illustrated that all tumour cell lines, irrespective of HPV status, expressed similarly moderate levels of MMP-14 compared to the chemonaive controls. We detected decreased reactivity with rising concentration of imatinib and with increasing time of incubation from 48 to $240 \mathrm{~h}$ in the HNSCC14C, HNSCC11A and CERV196 cells. Notably, we detected strong immunostaining for MMP-14 in the p16-positive SCC line (CERV196) only after $48 \mathrm{~h}$ of imatinib $(18 \mu \mathrm{mol} /$ ml) treatment (Table I). Compared to the differences in dose escalation, we showed stronger immunostaining for MMP-14 in all incubated SCC cell lines after incubation with imatinib at a lower concentration of $18 \mu \mathrm{mol} / \mathrm{ml}$ (Table I). However, after treatment with 5-FU in the CERV196 cells, we found slightly increased reactivity for MMP-14 only after $72 \mathrm{~h}$. In contrast, the immunohistochemical studies against MMP-14 showed slightly increased reactivity for MMP-14 only after $240 \mathrm{~h}$ of 5-FU treatment in the HNSCC11A cells. In HNSCC14C, we detected no positive reactivity for MMP-14 (Fig. 1; Table I).

ELISA of total protein expression in HNSCC11A, HNSCC14C and CERV196 cells. To analyze the effect of 5-FU and imatinib on HNSCC cell lines and the HPV-positive cell line CERV196, we added increasing concentrations of two chemotherapeutical agents, imatinib $(18 \mu \mathrm{mol} / \mathrm{ml})$ and $5-\mathrm{FU}(5 \mu \mathrm{mol} / \mathrm{ml})$, to the cell cultures. In order to determine MMP-2 as well as MMP-14 expression in the supernatant of the cell lines, ELISA analysis 

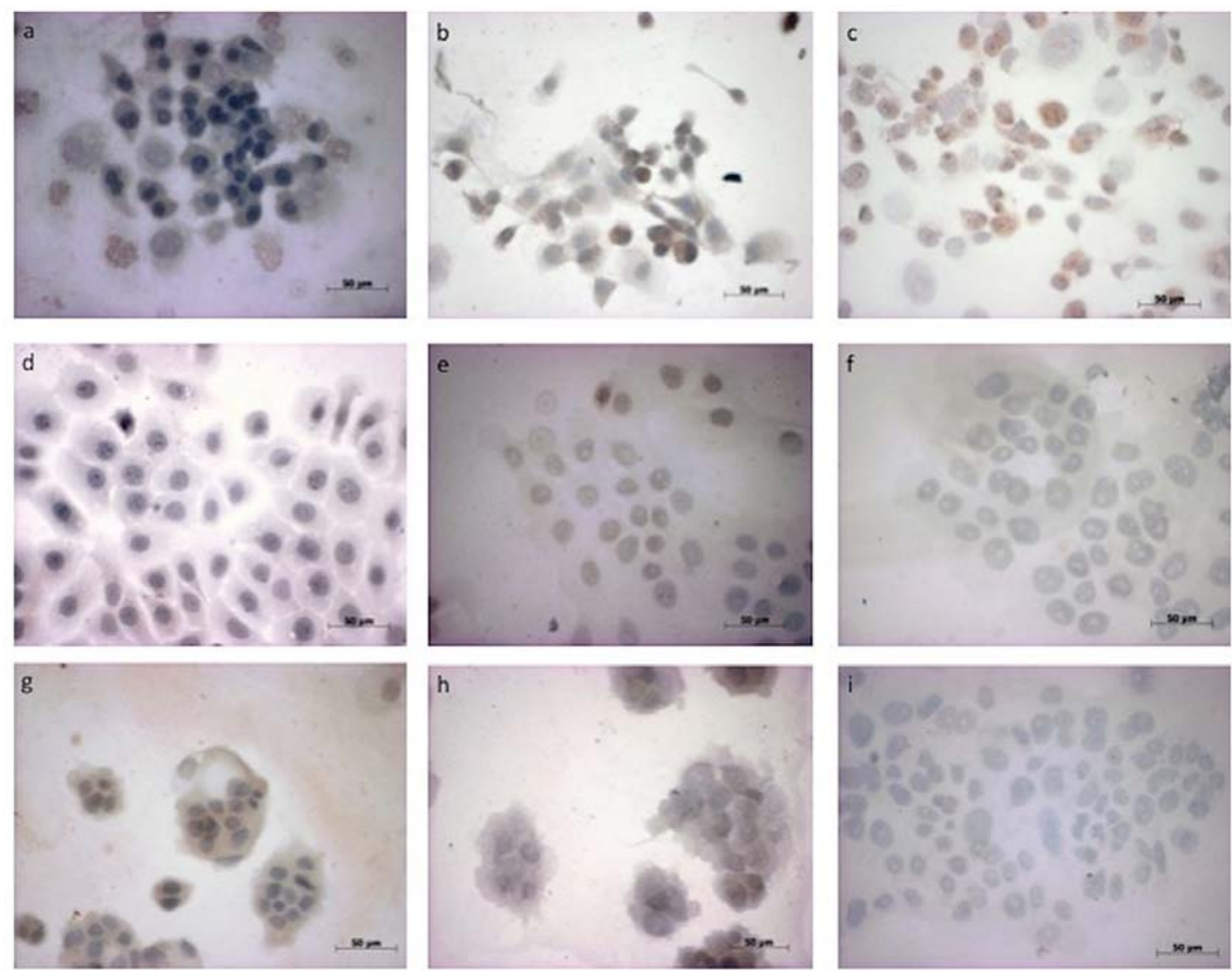

Figure 1. Negative control and decreasing immunohistochemical reactivity for MMP-14 after incubation with 5-FU ( $5 \mu \mathrm{mol} / \mathrm{ml})$ for $72 \mathrm{and} 240 \mathrm{~h}$ in the following cells lines: (a-c) HNSCC11A, (d-f) HNSCC14C, (g-i) CERV196.

was carried out $48,72,120,192$ and $240 \mathrm{~h}$ after the start of incubation.

Compared to the HPV-negative tumour cell lines, the negative controls of the CERV196 cells exhibited higher total protein expression levels. The HPV16-positive SCC cell line was vulnerable to 5-FU and imatinib therapy. However, the CERV196 cells showed only a less higher decreasing of total protein expression after $240 \mathrm{~h}$ of treatment with 5-FU. In summary, the HPV-negative cell lines showed no significant differences after treatment with imatinib and 5-FU. We found a lower expression of total protein after prolonged treatment time with imatinib in the HNSCC11A and HNSCC14C cells compared to incubation with 5-FU. The drug concentration had no significant influence on the expression of total protein (Fig. 2).

ELISA of MMP-2 expression in HNSCC11A, HNSCC14C and CERV196 cells. In summary, we detected weaker expression of MMP-2 in all three cell lines, particularly in the CERV196 cells. In the p16-positive SCC cells, maximal reduction of MMP-2 was noted after $72 \mathrm{~h}$ of imatinib treatment $(0.22 \mathrm{ng} / \mathrm{ml} ; \mathrm{p}<0.0075)$. We found a distinct trend towards reduction in MMP-2 expression after prolonged treatment time with imatinib in the HNSCC11A, HNSCC14C and CERV196 cells. A significant time-dependent effect was noted in the HNSCC11A cells when exposed to imatinib $(18 \mu \mathrm{mol} / \mathrm{ml})$ within the $48-240 \mathrm{~h}$ time frame $(\mathrm{p}<0.018)$. A statistically significant impact on MMP-2 expression was found in the HNSCC14C and CERV196 cells after 3 days of incubation with imatinib $(\mathrm{p}<0.008)$. Notably, compared to the HPV-negative cell lines, in the CERV196 cells, an increase in
MMP-2 expression was noted after prolonged treatment time with 5-FU $(5 \mu \mathrm{mol} / \mathrm{ml})$. We detected suppression of MMP-2 only after a prolonged treatment time with 5-FU in the HNSCC11A and HNSCC14C cells. However, a statistically significant impact on MMP-2 suppression was noted after $192 \mathrm{~h}$ of treatment with 5-FU $(p<0.0052)$ in the HNSCC11A cells. In the CERV196 and HNSCC14C cells, no significant downregulation of MMP-2 was found following treatment with 5 -FU $(5 \mu \mathrm{mol} / \mathrm{ml})$. The concentration of imatinib or 5-FU had no statistically significant impact on MMP-2 expression (Fig. 3; Table II).

ELISA of MMP-14 expression in HNSCC11A, HNSCC14C and CERV196 cells. In contrast to MMP-2, stronger expression of MMP-14 was exhibited in all three cell lines, particularly in the HNSCC14C cells. CERV196 cells showed a consistent trend towards an incubation time-dependent reduction in MMP-14, particularly after treatment with imatinib $(18 \mu \mathrm{mol} / \mathrm{ml})$. We detected a statistically significant impact on MMP-14 suppression in the p16-positive SCC cells only after a 192-h treatment with imatinib $(\mathrm{p}<0.023)$. However, the effect of the incubation with imatinib on CERV196 cells was less evident than on the HNSCC11A and HNSCC14C cell lines. In the HNSCC11A cells, maximal reduction in MMP-14 expression was measured after $192 \mathrm{~h}$ of imatinib $(18 \mu \mathrm{mol} / \mathrm{ml})$ treatment. Significant time-dependent suppression of MMP-14 was detected in the HNSCC14C cells when exposed to imatinib $(18 \mu \mathrm{mol} / \mathrm{ml})$ for $72-240 \mathrm{~h}(\mathrm{p}<0.0023)$. We showed a statistically significant impact on MMP-14 expression in the HNSCC11A cells after 3 days $(\mathrm{p}<0.02)$. 
Table II. Enzyme-linked immunosorbent assay (ELISA) for MMP-2 expression in HNSCC11 A, HNSCC14C and CERV196 cells after incubation with 5-FU and imatinib.

MMP-2 expression $\mathrm{ng} / \mathrm{ml}$ (p-value)

Time of incubation (h)

\begin{tabular}{ccc}
\hline Control & imatinib $(18 \mu \mathrm{mol} / \mathrm{ml})$ & $5-\mathrm{FU}(5 \mu \mathrm{mol} / \mathrm{ml})$ \\
Mean value & Mean value (p-value) & Mean value (p-value)
\end{tabular}

HNSCC11A cells

\begin{tabular}{|c|c|c|c|c|}
\hline 48 & 0.60 & $0.4(0.0044)$ & 0.54 & $(0.5878)$ \\
\hline 72 & 0.66 & $0.38(0.0178)$ & 0.67 & $(0.9961)$ \\
\hline 120 & 0.73 & $0.37(0.0154)$ & 0.48 & (0.1197) \\
\hline 192 & 0.96 & $0.59(0.0014)$ & 0.5 & $(0.0051)$ \\
\hline 240 & 0.80 & $0.27(0.0006)$ & 0.69 & $(0.4657)$ \\
\hline \multicolumn{5}{|c|}{ HNSCC $14 \mathrm{C}$ cells } \\
\hline 48 & 0.59 & $0.47(0.3357)$ & \multicolumn{2}{|c|}{$0.573(0.6921)$} \\
\hline 72 & 0.75 & $0.42(0.0030)$ & 0.6 & $(0.2573)$ \\
\hline 120 & 0.71 & $0.38(0.0122)$ & 0.57 & $(0.2607)$ \\
\hline 192 & 0.60 & $0.35(0.0415)$ & 0.42 & $(0.3818)$ \\
\hline 240 & 0.62 & $0.3(0.0408)$ & 0.54 & $(0.6742)$ \\
\hline \multicolumn{5}{|c|}{ CERV196 cells } \\
\hline 48 & 0.34 & $0.26(0.9785)$ & 0.32 & $(0.9934)$ \\
\hline 72 & 0.41 & $0.22(0.0073)$ & 0.33 & $(0.7349)$ \\
\hline 120 & 0.41 & $0.25(0.2221)$ & 0.41 & $(0.9523)$ \\
\hline 192 & 0.57 & $0.33(0.0718)$ & 0.52 & $(0.9873)$ \\
\hline 240 & 0.57 & $0.28(0.0632)$ & 0.76 & $(0.7753)$ \\
\hline
\end{tabular}

Mean values and statistical correlation compared to the negative control ( $\mathrm{p}$-value, Dunnett's test, $\mathrm{n}=3$ ) are shown. Bold font indicates statistically significant differences after treatment with imatinib particularly in HNSCC11A and HNSCC14C cells.

A Protein expression in HNSCC11A

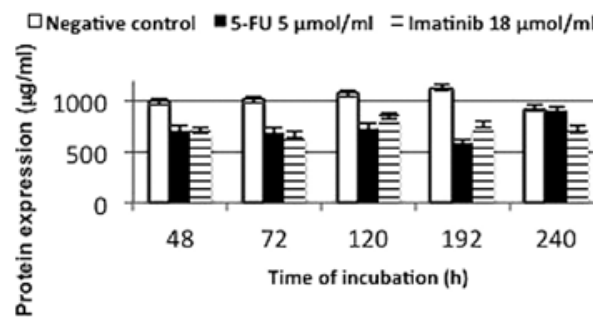

C Protein expression in CERV196

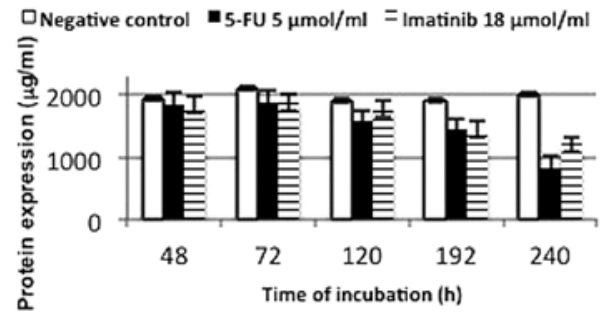

B Protein expression in HNSCC14C

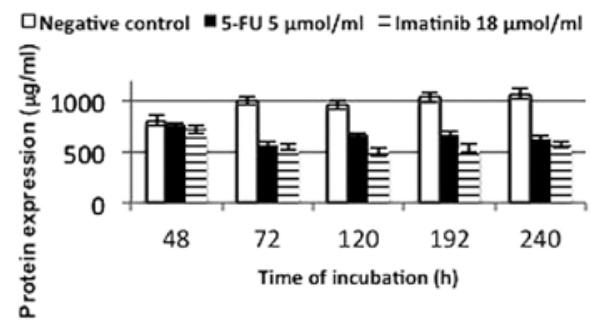

Figure 2. Total protein expression in (A) HNSCC11A, (B) HNSCC14C and (C) CERV196 cells after incubation with 5-FU (5 $\mu \mathrm{mol} / \mathrm{ml}) \mathrm{and} \mathrm{imatinib}(18 \mu \mathrm{mol} /$ $\mathrm{ml}$ ). Protein expression decreased over time after treatment with 5-FU and imatinib.

In the CERV196 and HNSCC14C cells, we detected less MMP-14 suppression after treatment with 5 -FU $(5 \mu \mathrm{mol} / \mathrm{ml})$. Notably, 5-FU $(5 \mu \mathrm{mol} / \mathrm{ml})$ reduced MMP-14 expression in the HNSCC11A cells between 72 and $192 \mathrm{~h}$ of treatment. A statistically significant downregulation of MMP-14 was found in the HNSCC11A only after a 72-h incubation with imatinib 

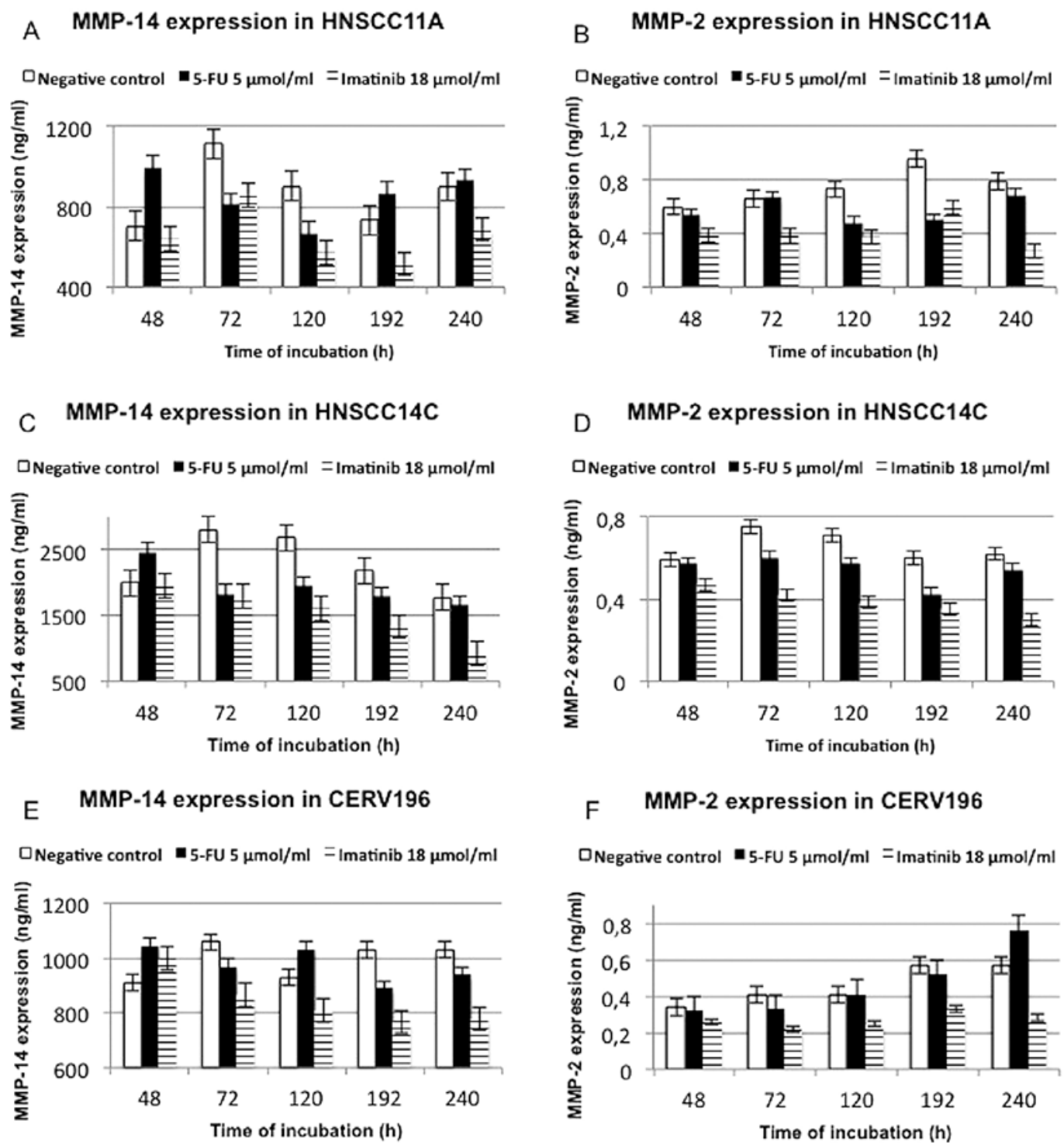

Figure 3. Expression of MMP-14 and MMP-2 in head and neck squamous cancer cells and CERV196 cells after incubation with 5-FU (5 $\mu$ mol/ml) and imatinib (18 $\mu \mathrm{mol} / \mathrm{ml})$. MMP-14 and MMP-2 expression in (A and B) HNSCC11A, (C and D) HNSCC14C and (E and F) CERV196 cells after incubation with 5-FU and imatinib.

$(18 \mu \mathrm{mol} / \mathrm{ml})(\mathrm{p}<0.02)$. Concentration of imatinib and 5-FU did not significantly influence the effect of MMP-14 suppression in any of the cell lines (Fig. 3; Table III).

\section{Discussion}

HNSCC is the sixth most common cancer in regards to incidence worldwide. Known risk factors are tobacco use and alcohol consumption, which appear to have a synergistic effect. In addition, a subgroup of HNSCC is caused by infection with high-risk types of HPV, particularly cancer of the oropharynx (34). The poor survival rate can be attributed to local invasion, cervical lymph node dissemination, distant metastasis and second primary cancers (35). To improve survival, it is important to investigate phenotypic changes in HNSCC and examine how HNSCC cells destroy the basement membrane, invade and metastasise. HNSCCs show a high propensity for local recurrence after treatment (36). A combination of chemotherapy and radiotherapy improves the poor prognosis of advanced HNSCC patients. Concomitant treatment of chemoradio- therapy has less improved the overall and 5-year survival rates of patients with advanced stage disease; however, the locoregional control rate could be improved. Multimodal tumour therapy often reduces the quality of life of patients, making the psychosocial consequences of HNSCC greater than that of other neoplasms (5). To further improve the survival rate, particularly for unresectable HNSCC, innovative strategies and targeted therapies must be analysed. However, HNSCCs arise from the accumulation of epigenetic and genetic factors, including the ability to escape apoptosis, insensitivity to antigrowth signals, abnormalities in cancer-associated signalling pathways, limitless replicative potential, self-sufficiency in growth signals, increased angiogenesis, metastasis and invasion (36). Degrading of the ECM by MMPs is one of the most critical steps in tumour progression, including tumour growth, invasion, metastasis and angiogenesis (24). The present study aimed to detect altered expression of MMP-2 and MMP-14 in p16-negative (HNSCC11A, HNSCC14C) and p16-positive SCC cell lines (CERV196). PTKs are fundamental elements of the signalling pathway that may also be targets for anticancer 
Table III. Enzyme-linked immunosorbent (ELISA) assay for MMP-14 expression in HNSCC11A, HNSCC14C, and CERV196 cells after incubation with 5-FU and imatinib.

\begin{tabular}{|c|c|c|c|c|}
\hline \multirow[b]{2}{*}{ Incubation time $(\mathrm{h})$} & \multicolumn{4}{|c|}{ MMP-14 expression, ng/ml (p-value) } \\
\hline & $\begin{array}{c}\text { Control } \\
\text { Mean value }\end{array}$ & $\begin{array}{l}\text { imatinib (1 } \\
\text { Mean valu }\end{array}$ & $\begin{array}{l}18 \mu \mathrm{mol} / \mathrm{ml} \text { ) } \\
\text { de ( } \mathrm{p} \text {-value) }\end{array}$ & $\begin{array}{c}5 \text {-FU }(5 \mu \mathrm{mol} / \mathrm{ml}) \\
\text { Mean value (p-value) }\end{array}$ \\
\hline \multicolumn{5}{|l|}{ HNSCC11A cells } \\
\hline 48 & 703.33 & 638.33 & $(0.8027)$ & $997.33(0.1162)$ \\
\hline 72 & 1112.77 & 855.87 & $(\mathbf{0 . 0 1 8 9})$ & $811.33(0.1017)$ \\
\hline 120 & 900.13 & 570 & $(0.2715)$ & $669 \quad(0.6393)$ \\
\hline 192 & 732.67 & 514.33 & $(0.5166)$ & $865.33(0.5651)$ \\
\hline 240 & 899.33 & 687.3 & $(0.1510)$ & $931 \quad(0.9862)$ \\
\hline \multicolumn{5}{|l|}{ HNSCC14C cells } \\
\hline 48 & 1989.1 & 1944 & $(0.9838)$ & $2462.53(0.7141)$ \\
\hline 72 & 2803.8 & 1788 & $(<0.0001)$ & $1827.03(0.0019)$ \\
\hline 120 & 2677.67 & 1605.33 & $(<0.0001)$ & $1939 \quad(0.0135)$ \\
\hline 192 & 2181 & 1331.67 & $(\mathbf{0 . 0 0 2 2})$ & $1793.07(0.5744)$ \\
\hline 240 & 1775.67 & 917.33 & $(0.0001)$ & $1660.67(0.8473)$ \\
\hline \multicolumn{5}{|l|}{ CERV196 cells } \\
\hline 48 & 910.57 & 998.33 & $(0.7653)$ & $1045.53(0.8791)$ \\
\hline 72 & 1060 & 864.48 & $(0.2979)$ & $967.81(0.3704)$ \\
\hline 120 & 930 & 808.33 & $(0.5715)$ & $1031 \quad(0.7483)$ \\
\hline 192 & 1029.67 & 768.77 & $(0.0222)$ & $888.36(0.7462)$ \\
\hline 240 & 1031 & 778.67 & $(0.0569)$ & $940.04(0.3486)$ \\
\hline
\end{tabular}

Mean values and statistical correlation compared to the negative control ( $\mathrm{p}$-value, Dunnett's test, $\mathrm{n}=3$ ) are shown. Bold font indicates statistically significant differences after treatment with imatinib particularly in HNSCC14C.

therapy. Imatinib is a specific protein tyrosine-kinase inhibitor for c-Abl and BCR-Abl and was originally designed to block the BCR-Abl tyrosine kinase in chronic myeloid leukemia (37). Imatinib also showed an inhibitory effect on the catalytic activity of PDGFR and c-kit tyrosine kinases. It is used for the treatment of several malignancies, such as colon adenocarcinoma and non-small cell lung cancer (37-39). The aim of the present study was to investigate the effects of imatinib and 5-FU on HPV16-associated HNSCC compared to non-HPVinduced HNSCC and their impact on the expression of MMP-2 and MMP-14 in order to examine the potency of chemotherapeutic agents in HNSCC cell lines. The concentration of imatinib and the time of stimulation used in our analyses were defined after performing cell proliferating assays.

Compared to the HPV-negative tumour cell lines, negative controls of CERV196 cells showed lower expression of MMP-2. MMP-2 (gelatinase A) is known to play an important role in the degradation of the basement membrane and ECM to promote tumour cell invasion and metastasis. MMP-2 expression correlates with local invasion, lymph node metastasis and poor prognosis. In human colon cancer cells, imatinib was shown to be a powerful growth inhibitor and an effective suppressor of stromal-induced stimulation of cancer cell growth and activation of proMMP-2 (37). Recently, an experimental study showed that HPV16-positive lung cancer cells exhibit upregulation of pro-angiogenic MMP-2 and MMP-9 through induction of IL- 8 expression. Therefore, it may be concluded that the cytokines induced by HPV infection may work together to confer malignant and tumorigenic potential on the infected cells by promoting pathways of growth, angiogenic and metastatic characteristics (40). Studies of uterine cervical neoplasms also indicate that HPV oncoproteins promote MMP imbalance (41). Higher expression of MMP-14 and MMP-2 has been noted in HPV-positive cervical cancerderived cells. Notably, an associated downregulation of RECK, a membrane-bound protein that has an inhibitory effect on the transcription, synthesis and activation of MMPs, was shown in HPV16 E7-positive cervical carcinoma cell lines (41). A decrease in RECK expression levels was found in precancerous and cancerous lesions (41). We found a distinct trend towards reduction in MMP-2 expression after prolonged treatment time with imatinib. In p16-positive cells, we detected a maximal reduction in MMP-2 after $72 \mathrm{~h}$ of imatinib treatment. Several growth factors, such as transforming growth factor $\beta$ (TGF $\beta 1$ ), stem cell factor (SCF), hepatocyte growth factor (HGF) or insulin-like growth factor (IGF), were found to be generated by fibroblasts and can activate MMP-induced tumour growth stimulation by proteolytic cleavage. In the HNSCC11A cells, a statistically significant time-dependent downregulation of MMP-2 by imatinib was revealed. After treatment with 5-FU, we detected a decrease in suppression of MMP-2 and MMP-14 only after prolonged treatment time. Compared to the HPV-negative cell lines, in the CERV196 cells, an increase in MMP-2 expression was noted after prolonged treatment 
time with 5-FU. MMP2 mRNA speaking is also well for the functional important role of this proteinase in the process of carcinoma cell invasion and epithelial-mesenchymal transition (EMT) in oral squamous cell carcinoma cells (42). Qiao et al suggested that the transcription factor Snail influences the upregulation of MMP-2 expression initiating EMT in oral squamous cell carcinoma (43). However, relevant downregulation of MMP-2 such as by imatinib possibly could inhibit promotion of EMT and invasion. Using 5-FU in the past, we detected only a slight alteration in $\beta$-catenin expression in p16-positive and p16-negative SCC cell lines (44). 5-FU is an established agent on which all curative therapeutic approaches to different neoplasms are based. However, little effect has been observed when 5-FU is used as a single agent. Tumour cells are resistant to 5-FU due to dynamic regulation of the pyrimidine network, adopting autonomous strategies for primary and secondary resistance (37). In additional studies, data suggest that the orotate phosphoribosyl-transferase (OPRT) gene enhances the chemotherapeutic effect of 5-FU in HNSCC cells in vitro. However, the level of OPRT expression could be used as a predictive indicator of 5-FU efficacy against HNSCC (45). On the other hand, in different types of tumours, dihydropyrimidine dehydrogenase (DPD), a natural enzyme that influences pyrimidine degradation, was detected. This enzyme is responsible for the rate-limiting step in the catabolism of 5-FU that accounts for $>80 \%$ of its elimination (46-49). Thus, carcinomas with a high DPD level are more resistant to 5-FU than carcinomas with low levels of DPD (46).

We detected higher expression of MMP-14 than that of MMP-2 in all three SCC cell lines. MMP-14 is known to activate gelatinase MMP-2 (50). However, there may be an association between the fact that MMP-14 activates MMP-2 and the higher expression of MMP-14 detected in all three cell lines, particularly in the HPV-negative HNSCC cell lines. In p16-positive and HNSCC14C cells, we found a consistent trend towards an incubation time-dependent reduction in MMP-14 levels, particularly after treatment with imatinib. MMP-14 (also called membrane type 1 MMP, MT1-MMP) is thereby considered a key protein in physiological and pathological processes from normal cell development to cancer cell growth, promoting tissue remodelling, invasion, and metastasis in malignant tumours [e.g., oral squamous cell cancer (OSCC)] (51). Invasion through collagen networks and collagenolysis is dependent on MMP-14, not on secreted MMPs (52). The interaction of MMP-14 with the membrane-associated glycoprotein CD44 activates a migratory front (53). Recently, MMP-14-dependent invasion and metastasis were effectively inhibited by intraperitoneal administration of a monoclonal MMP-14 antibody in a model of advanced peritoneal ovarian cancer (25).

Notably, CERV196 cells exhibited higher expression of total protein. However, HPV-positive tumour cells have a stronger basal metabolism in general. 5-FU had a stronger influence on the alteration of the expression of total protein, particularly in the p16-positive SCC cells.

The present study did not confirm the clinically substantiated increase in chemosensitivity of p16-positive tumour cells, but we did detect differences in the alteration of MMP-2 and MMP-14 expression after treatment with the chemotherapeutic agents. We found higher suppression of MMP-2 in CERV196 cells after incubation with imatinib. However, for therapeutic treatment of HNSCC, knowledge of the HPV-status is still an important factor. In conclusion, we detected expression of MMP-2 and MMP-14 in the three p16-positive and -negative SCC cell lines. We found that imatinib exhibited a strong inhibitory effect on the downregulation of MMP expression in the HNSCC cell lines via the blockage of signal transduction of PTK receptors (37). Given these results and the low toxicity of imatinib, further studies are needed to examine the potency of imatinib in HNSCC treatment and to find innovative strategies and targeted therapies to improve the clinical outcome of patients with HNSCC, depending on HPV status.

\section{Acknowledgements}

The authors would like to thank Petra Prohaska for her excellent technical assistance and Dr. C. Weiss for the brilliant assistance in the statistical analysis.

\section{References}

1. Leemans CR, Braakhuis BJ and Brakenhoff RH: The molecular biology of head and neck cancer. Nat Rev Cancer 11: 9-22, 2011.

2. Bodnar M, Szylberg L, Kazmierczak W and Marszalek A: Differentiated expression of membrane type metalloproteinases (MMP-14, MMP-15) and pro-MMP2 in laryngeal squamous cell carcinoma. A novel mechanism. J Oral Pathol Med 42: 267-274, 2013.

3. Oliveira LR and Ribeiro-Silva A: Prognostic significance of immunohistochemical biomarkers in oral squamous cell carcinoma. Int J Oral Maxillofac Surg 40: 298-307, 2011.

4. de Vicente JC, Lequerica-Fernandez P, Santamaria J and Fresno MF: Expression of MMP-7 and MT1-MMP in oral squamous cell carcinoma as predictive indicator for tumor invasion and prognosis. J Oral Pathol Med 36: 415-424, 2007.

5. Massano J, Regateiro FS, Januario G and Ferreira A: Oral squamous cell carcinoma: review of prognostic and predictive factors. Oral Surg Oral Med Oral Pathol Oral Radiol Endod 102: 67-76, 2006.

6. Schultz JD, Rotunno S, Riedel F, et al: Synergistic effects of imatinib and carboplatin on VEGF, PDGF and PDGF-R $\alpha / \beta$ expression in squamous cell carcinoma of the head and neck in vitro. Int J Oncol 38: 1001-1012, 2011.

7. Myoung H, Kim MJ, Lee JH, Ok YJ, Paeng JY and Yun PY: Correlation of proliferative markers (Ki-67 and PCNA) with survival and lymph node metastasis in oral squamous cell carcinoma: a clinical and histopathological analysis of 113 patients. Int J Oral Maxillofac Surg 35: 1005-1010, 2006.

8. Sepiashvili L, Hui A, Ignatchenko V, et al: Potentially novel candidate biomarkers for head and neck squamous cell carcinoma identified using an integrated cell line-based discovery strategy. Mol Cell Proteomics 11: 1404-1415, 2012.

9. Bonner JA, Harari PM, Giralt J, et al: Radiotherapy plus cetuximab for locoregionally advanced head and neck cancer: 5-year survival data from a phase 3 randomised trial, and relation between cetuximab-induced rash and survival. Lancet Oncol 11: 21-28, 2010.

10. Nair $S$ and Pillai MR: Human papillomavirus and disease mechanisms: relevance to oral and cervical cancers. Oral Dis 11: 350-359, 2005.

11. Sudhoff HH, Schwarze HP, Winder D, et al: Evidence for a causal association for HPV in head and neck cancers. Eur Arch Otorhinolaryngol 268: 1541-1547, 2011.

12. Schultz JD, Sommer JU, Hoedt S, et al: Chemotherapeutic alteration of $\beta$-catenin and c-kit expression by imatinib in p16-positive squamous cell carcinoma compared to HPV-negative HNSCC cells in vitro. Oncol Rep 27: 270-280, 2012.

13. Kreimer AR, Clifford GM, Boyle P and Franceschi S: Human papillomavirus types in head and neck squamous cell carcinomas worldwide: a systematic review. Cancer Epidemiol Biomarkers Prev 14: 467-475, 2005.

14. Wang Z, Sturgis EM, Zhang Y, et al: Combined p53-related genetic variants together with HPV infection increase oral cancer risk. Int J Cancer 131: E251-E258, 2012. 
15. Shiboski $\mathrm{CH}$, Schmidt BL and Jordan RC: Tongue and tonsil carcinoma: increasing trends in the U.S. population ages 20-44 years. Cancer 103: 1843-1849, 2005

16. Tezal M, Scannapieco FA, Wactawski-Wende J, et al: Local inflammation and human papillomavirus status of head and neck cancers. Arch Otolaryngol Head Neck Surg 138: 669-675, 2012.

17. Hay ED: The mesenchymal cell, its role in the embryo, and the remarkable signaling mechanisms that create it. Dev Dyn 233: 706-720, 2005

18. Tester AM, Ruangpanit N, Anderson RL and Thompson EW: MMP-9 secretion and MMP-2 activation distinguish invasive and metastatic sublines of a mouse mammary carcinoma system showing epithelial-mesenchymal transition traits. Clin Exp Metastasis 18: 553-560, 2000.

19. Stamenkovic I: Extracellular matrix remodelling: the role of matrix metalloproteinases. J Pathol 200: 448-464, 2003.

20. Al-Azri AR, Gibson RJ, Keefe DM and Logan RM: Matrix metalloproteinases: do they play a role in mucosal pathology of the oral cavity? Oral Dis 19: 347-359, 2013.

21. Martins VL, Caley M and O'Toole EA: Matrix metalloproteinases and epidermal wound repair. Cell Tissue Res 351: 255-268, 2013.

22. de Andres MC, Kingham E, Imagawa K, et al: Epigenetic regulation during fetal femur development: DNA methylation matters. PLoS One 8: e54957, 2013.

23. Tamamura $\mathrm{R}$, Nagatsuka $\mathrm{H}$, Siar $\mathrm{CH}$, et al: Comparative analysis of basal lamina type IV collagen $\alpha$ chains, matrix metalloproteinases-2 and -9 expressions in oral dysplasia and invasive carcinoma. Acta Histochem 115: 113-119, 2013.

24. Folgueras AR, Pendas AM, Sanchez LM and Lopez-Otin C: Matrix metalloproteinases in cancer: from new functions to improved inhibition strategies. Int J Dev Biol 48: 411-424, 2004.

25. Kaimal R, Aljumaily R, Tressel SL, et al: Selective blockade of matrix metalloprotease-14 with a monoclonal antibody abrogates invasion, angiogenesis, and tumor growth in ovarian cancer. Cancer Res 73: 2457-2467, 2013.

26. Mallis A, Teymoortash A, Mastronikolis NS, Werner JA and Papadas TA: MMP-2 expression in 102 patients with glottic laryngeal cancer. Eur Arch Otorhinolaryngol 269: 639-642, 2012

27. Gorogh T, Beier UH, Baumken J, et al: Metalloproteinases and their inhibitors: influence on tumor invasiveness and metastasis formation in head and neck squamous cell carcinomas. Head Neck 28: 31-39, 2006.

28. Bran B, Bran G, Hormann K and Riedel F: The platelet-derived growth factor receptor as a target for vascular endothelial growth factor-mediated anti-angiogenetic therapy in head and neck cancer. Int J Oncol 34: 255-261, 2009.

29. Heinrich MC, Griffith DJ, Druker BJ, Wait CL, Ott KA and Zigler AJ: Inhibition of c-kit receptor tyrosine kinase activity by STI 571, a selective tyrosine kinase inhibitor. Blood 96: 925-932, 2000.

30. Levitzki A: Tyrosine kinase inhibitors: views of selectivity, sensitivity, and clinical performance. Annu Rev Pharmacol Toxicol 53: 161-185, 2013

31. Angelini S, Ravegnini G, Fletcher JA, Maffei F and Hrelia P. Clinical relevance of pharmacogenetics in gastrointestinal stromal tumor treatment in the era of personalized therapy. Pharmacogenomics 14: 941-956, 2013.

32. Rutkowski $\mathrm{P}$ and Gronchi A: Efficacy and economic value of adjuvant imatinib for gastrointestinal stromal tumors. Oncologist 18: 689-696, 2013.

33. Longley DB, Harkin DP and Johnston PG: 5-Fluorouracil: mechanisms of action and clinical strategies. Nat Rev Cancer 3 : $330-338,2003$

34. Klussmann JP, Preuss SF and Speel EJ: Human papillomavirus and cancer of the oropharynx. Molecular interaction and clinical implications. HNO 57: 113-122, 2009 (In German).

35. Scanlon CS, Van Tubergen EA, Inglehart RC and D'Silva NJ: Biomarkers of epithelial-mesenchymal transition in squamous cell carcinoma. J Dent Res 92: 114-121, 2013.

36. Koontongkaew S: The tumor microenvironment contribution to development, growth, invasion and metastasis of head and neck squamous cell carcinomas. J Cancer 4: 66-83, 2013.
37. Stahtea XN, Roussidis AE, Kanakis I, et al: Imatinib inhibits colorectal cancer cell growth and suppresses stromal-induced growth stimulation, MT1-MMP expression and pro-MMP2 activation. Int J Cancer 121: 2808-2814, 2007.

38. Tsao AS, Liu S, Fujimoto J, et al: Phase II trials of imatinib mesylate and docetaxel in patients with metastatic non-small cell lung cancer and head and neck squamous cell carcinoma. J Thorac Oncol 6: 2104-2111, 2011.

39. Popow-Wozniak A, Wozniakowska A, Kaczmarek L, MalickaBlaszkiewicz M and Nowak D: Apoptotic effect of imatinib on human colon adenocarcinoma cells: influence on actin cytoskeleton organization and cell migration. Eur J Pharmacol 667: 66-73, 2011

40. Shiau MY, Fan LC, Yang SC, et al: Human papillomavirus up-regulates MMP-2 and MMP-9 expression and activity by inducing interleukin-8 in lung adenocarcinomas. PLoS One 8: e54423, 2013.

41. Cardeal LB, Boccardo E, Termini L, et al: HPV16 oncoproteins induce MMPs/RECK-TIMP-2 imbalance in primary keratinocytes: possible implications in cervical carcinogenesis. PLoS One 7: e33585, 2012.

42. Richter P,Umbreit C,Franz M, et al: EGF/TGFbeta1 co-stimulation of oral squamous cell carcinoma cells causes an epithelial-mesenchymal transition cell phenotype expressing laminin 332. J Oral Pathol Med 40: 46-54, 2011.

43. Qiao B, Johnson NW and Gao J: Epithelial-mesenchymal transition in oral squamous cell carcinoma triggered by transforming growth factor-beta1 is Snail family-dependent and correlates with matrix metalloproteinase-2 and -9 expressions. Int J Oncol 37: 663-668, 2010.

44. Umbreit C, Aderhold C, Faber A, et al: Unexpected alteration of $\beta$-catenin and $\mathrm{c}$-KIT expression by 5 -FU and docetaxel in p16-positive squamous cell carcinoma compared to HPV-negative HNSCC cells in vitro. Anticancer Res 33: 2457-2465, 2013.

45. Yasumatsu R, Nakashima T and Komune S: Overexpression of the orotate phosphoribosyl-transferase gene enhances the effect of 5-fluorouracil in head and neck squamous cell carcinoma in vitro. J Oncol 2012: 649605, 2012.

46. Milano G and Etienne MC: Potential importance of dihydropyrimidine dehydrogenase (DPD) in cancer chemotherapy. Pharmacogenetics 4: 301-306, 1994.

47. Jiang W, Lu Z, He Y and Diasio RB: Dihydropyrimidine dehydrogenase activity in hepatocellular carcinoma: implication in 5-fluorouracil-based chemotherapy. Clin Cancer Res 3: 395-399, 1997.

48. Kawasaki G, Yoshitomi I, Yanamoto S, Yamada S, Mizuno A and Umeda M: Expression of thymidylate synthase and dihydropyrimidine dehydrogenase in primary oral squamous cell carcinoma and corresponding metastases in cervical lymph nodes: association with the metastasis suppressor CD82. Anticancer Res 31: 3521-3526, 2011.

49. Tamatani T, Ferdous T, Takamaru N, et al: Antitumor efficacy of sequential treatment with docetaxel and 5-fluorouracil against human oral cancer cells. Int J Oncol 41: 1148-1156, 2012.

50. Wang P, Nie J and Pei D: The hemopexin domain of membranetype matrix metalloproteinase-1 (MT1-MMP) is not required for its activation of proMMP2 on cell surface but is essential for MT1-MMP-mediated invasion in three-dimensional type I collagen. J Biol Chem 279: 51148-51155, 2004.

51. Weng CJ, Chen MK, Lin CW, Chung TT and Yang SF: Single nucleotide polymorphisms and haplotypes of MMP-14 are associated with the risk and pathological development of oral cancer. Ann Surg Oncol 19 (Suppl 3): S319-S327, 2012.

52. Sabeh F, Li XY, Saunders TL, Rowe RG and Weiss SJ: Secreted versus membrane-anchored collagenases: relative roles in fibroblast-dependent collagenolysis and invasion. J Biol Chem 284: 23001-23011, 2009.

53. Zarrabi K, Dufour A, Li J, et al: Inhibition of matrix metalloproteinase 14 (MMP-14)-mediated cancer cell migration. J Biol Chem 286: 33167-33177, 2011. 